\title{
IFAS Assessment of Non-native Plants in Florida's Natural Areas: Status Assessment ${ }^{1}$
}

\author{
Alison M. Fox, Doria R. Gordon, Joan A. Dusky, Linda Tyson, Randall K. Stocker, Kenneth A. \\ Langeland, and Aimee L. Cooper ${ }^{2}$
}

\section{Purpose}

The purpose of the IFAS Assessment of Non-Native Plants in Florida's Natural Areas (IFAS Assessment) is to provide a well-defined system for distinguishing invasive, non-native plant species from those that are not invasive in Florida's natural areas. The IFAS Assessment conclusions allow consistent description and categorization of non-native plants in all IFAS Extension publications. The conclusions are intended to prevent invasion - or reduce the likelihood of continued invasion - of non-native species in Florida's natural systems. Development of a common basis for decisions will increase consistency and understanding of recommendations made by IFAS personnel about these species. The IFAS Assessment has specific requirements for documentation to support all relevant evidence, which reinforces the transparency and credibility of the process. The IFAS Assessment is intended to be useful in developing priorities for research and management efforts, and can be adapted for use in other states.

(For definitions of terms as used in this document see Glossary, at the end).

The IFAS Assessment has three components: the Status Assessment (this document), the Predictive Tool, and the Infraspecific Taxon Protocol. All three components - along with a more detailed description of how the IFAS Assessment was developed - are available at http://plants.ifas.ufl.edu/assessment/.

The Status Assessment is only intended for plants that currently occur within Florida. It is not intended to provide evaluations of species that have not yet been introduced to the state. Those species would be

1. This document is SS-AGR-225, one of a series of the Agronomy Department, Florida Cooperative Extension Service, Institute of Food and Agricultural Sciences, University of Florida. Revised publication date: April 2009.

In IFAS Extension publications this document should be cited as:

Fox, A.M., D.R. Gordon, J.A. Dusky, L. Tyson, R.K. Stocker, K.A. Langeland, and A.L. Cooper (2009) IFAS Assessment of Non-Native Plants in Florida's Natural Areas: Status Assessment. Cited from the Internet December 2009, http://plants.ifas.ufl.edu/assessment/pdfs/status_assessment.pdf

2. Alison M. Fox, emeritus associate professor, Agronomy Department, University of Florida, Gainesville, FL; Doria R. Gordon, Director of Conservation Science, The Nature Conservancy and Courtesy Professor, Department of Biology, University of Florida, Gainesville, FL; Joan A. Dusky, professor and associate dean for Extension, University of Florida, Gainesville, FL; Linda Tyson, professor, Santa Fe Community College, Gainesville, FL; Randall K. Stocker, emeritus professor, Agronomy Department, University of Florida, Gainesville, FL; K. A. Langeland, professor, Agronomy Department and Center for Aquatic and Invasive Plants, University of Florida, Gainesville, FL; and Aimee L. Cooper, biological scientist, Agronomy Department and Center for Aquatic and Invasive Plants, University of Florida, Gainesville, FL.

The use of trade names in this publication is solely for the purpose of providing specific information. UF/IFAS does not guarantee or warranty the products named, and references to them in this publication do not signify our approval to the exclusion of other products of suitable composition.

The Institute of Food and Agricultural Sciences (IFAS) is an Equal Opportunity Institution authorized to provide research, educational information and other services only to individuals and institutions that function with non-discrimination with respect to race, creed, color, religion, age, disability, sex, sexual orientation, marital status, national origin, political opinions or affiliations. U.S. Department of Agriculture, Cooperative Extension Service, University of Florida, IFAS, Florida A. \& M. University Cooperative Extension Program, and Boards of County Commissioners Cooperating. Millie Ferrer-Chancy, Interim Dean 
assessed using the Predictive Tool, which uses the Australian Weed Risk Assessment (Pheloung et al. 1999) system adapted for use in Florida (Gordon et al. 2008)

(

http://plants.ifas.ufl.edu/assessment/pdfs/ predictive_tool.pdf).

Additionally, the Status Assessment directs use of the Predictive Tool for: 1) species that have not escaped into Florida's natural areas but are either recent arrivals to the state or are known to cause problems in areas with habitats and climate similar to Florida's habitats and climate; or 2) species for which there are proposed new uses that would result in higher propagule pressure2 in Florida (see question I-a-1, below).

In all likelihood, the Status Assessment will identify fewer than 1 percent of all non-native plant species in the state as showing ecological impacts in natural areas. The Status Assessment is designed to identify those non-native plant species that are invasive in areas of Florida where designated management objectives include the conservation of native biodiversity. A range of activities may be conducted in such areas, but those activities should be compatible with the conservation objective of the natural areas.

State and local governments and some private landowners, for example, manage natural areas both for economic values (recreation, grazing, forestry or other harvest values) and for conservation values. These areas with multiple uses would be designated as natural areas in the IFAS Assessment, with clearly identifiable "non-natural" edges disregarded. Species that invade only the identified edges-areas next to roads, trails, fire lanes, recent dredge spoil, expanses of bare soil, etc.- - will not be identified as invaders with impacts in natural areas because their persistence and spread is limited to those anthropogenically disturbed zones in the natural area. The Status Assessment does require the evaluation of species that not only spread along these artificially disturbed zones but disperse over 10 yards into more intact natural areas, however.
Furthermore, in a few cases, consideration for broad conservation objectives sometimes makes it advisable to designate certain anthropogenically disturbed areas as "natural" for the purposes of assessment. This is because anthropogenically disturbed areas can provide habitat for species of special concern (Threatened or Endangered species). Non-native species that have not been identified in this Assessment as invading natural areas because their spread is limited to anthropogenically disturbed areas may in fact be causing damaging impacts when Threatened or Endangered species are found and maintained in areas the non-natives have become established. In other words, species currently described by this Assessment as "Not considered a problem species at this time" could in fact be causing problems. Such cases should be referred to the Florida Endangered Plant Advisory Council (Secretary: Tyson Emery, FL Department of Agriculture and Consumer Services, Division of Plant Industry, Tel: (352) 372-3505 Ext. 162.)

\section{Objective}

The objective of the Status Assessment is to summarize relevant ecological, management and economic value information on species by latitudinal zones in Florida. This approach provides substantially more information than would be indicated by simple presence or absence of an "Invasive Species List." This information is summarized by four indices, Ecological Impacts, Potential for Expansion, Difficulty of Management and Economic Value. Wherever possible, predictive items have been avoided, and are directed to the Predictive Tool. Most questions have been reduced to simple, two-choice answers. The Status Assessment does not address economic impacts other than cost of control in natural areas and economic value (in this instance, economic value is described as value for forage, biomass, or remediation purposes only). Other economic data (lost revenue, management costs other than control in natural areas, etc.) should be included in any detailed risk-benefit analyses of the current, or future, infestations of a species.

Conclusions by latitudinal zone, drawn from the combined scores of the four indices, result in 
specific recommendations that can be made about the species by IFAS personnel. The conclusions include a period after which the species must be reassessed (either 2 or 10 years). However, any species may be reassessed whenever additional relevant information becomes available that might change the result of the Assessment. Thus, conclusions might change at any time.

The Status Assessment is generally applied at the species level. It is only applied independently to infraspecific taxa (e.g., cultivars, varieties, or sub-species) if these taxa can be clearly distinguished in the field and are not likely to revert to traits of the parent plants (throughout the Status Assessment, reference to the species under consideration could also refer to such distinct infraspecific taxa). Other infraspecific taxa may be proposed for assessment using the Infraspecific Taxon Protocol http://plants.ifas.ufl.edu/assessment/ infraspecific_taxon_protocol.html. This protocol uses the same conclusions as the Status Assessment. Although they are derived differently, the conclusions for these infraspecific taxa are reported along with conclusions for all species evaluated using any component of the IFAS Assessment.

\section{Use of the Assessment within IFAS}

Species are assessed by trained personnel under the supervision of the IFAS Invasive Plants Working Group (IPWG). The results of each assessment are made available to all IFAS state and county Extension faculty (hereafter "IFAS faculty") through a website based at the Center for Aquatic and Invasive Plants http://plants.ifas.ufl.edu/assessment with links to IFAS Extension websites. IFAS faculty dealing with non-native plant species in Florida are expected to be familiar with this assessment.

The Status Assessment places non-native plant species in categories (called "index categories"). These categories describe varying degrees of "Ecological Impacts," "Potential for Expansion," "Management Difficulty," and "Economic Value." Any IFAS Extension publications or newsletters, including those developed by county faculty, that refer to specific non-native plants in relation to the topics covered by this assessment (e.g., invasiveness, ecology, distribution, management, use, recommendations, and value) are required to include a reference to this assessment, and to use the terms and conclusions from the assessment when describing features of these plants. For example, "This species shows high ecological impacts such as causing long-term alterations in ecosystem processes," and, "This species is considered invasive and not recommended by IFAS faculty (IFAS Invasive Plant Working Group, 2008)." Additional information about how to cite the IFAS Assessment, its components, conclusions, and results can be found at:

http://plants.ifas.ufl.edu/assessment/pdfs/ citations_examples.pdf

The Status Assessment uses the index categories to define "conclusions" about the assessed species, including conclusions such as "Invasive and not recommended by IFAS faculty." Faculty making planting recommendations may choose to include "not recommended" plants in their publications if the conclusions from the assessment are clearly presented. In some situations, it is better public education to include a "not recommended" plant with the reasons it should be avoided than to leave the species out of the publication entirely.

The Status Assessment will be revised periodically, and content and conclusions may change substantially. Every IFAS Extension publication must conform to the assessment protocol in place at the time of that publication's final drafting and must be made to conform to the current assessment protocol when it is revised. The IPWG will continue to review all Extension pre-publications related to invasive plants, and will determine if the direction and intent of these provisions are being followed. Further details concerning the use of the IFAS Assessment system by IFAS faculty are provided at: http://plants.ifas.ufl.edu/assessment/pdfs/ useassess.pdf

\section{Structure of the Status Assessment}

The Status Assessment is divided into five main sections, one for determining where the plant is invading and the others corresponding to four indices 
of Ecological Impacts, Potential for Expansion,

Difficulty of Management, and Economic Value.

These sections are designated by Roman Numerals (I

- V). Assessment questions within these sections are

located in shadowed boxes which have sub-section

letters (I-a, I-b, etc.). Each separate question within a box has its own number which is in either Arabic

numerals, for questions that influence the order of progression through the Status Assessment (e.g., I-a

1., I-a 2.), or diminutive Roman numerals, for statements to which scores are assigned (e.g., II-a $i$, II-a ii). Three further sections that directly lead to conclusions have letters $A-C$ and are found at the end of the Status Assessment.

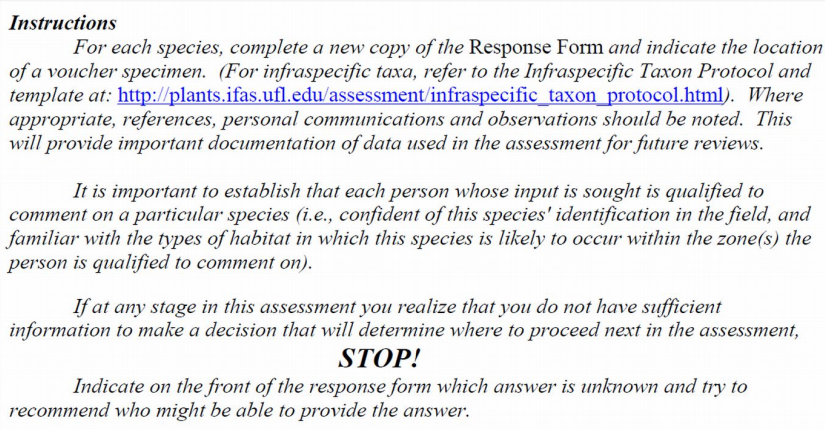
of a voucher specimen. (For infraspecific taxa, refer to the Infraspecific Taxon Protocol and template at: http://plants.ifas.ufl.edu/assessment/infraspecific_taxon_protocol.html). Where appropriate, references, personal communications and observations should be noted. This will provide important documentation of data used in the assessment for future reviews.

It is important to establish that each person whose input is sought is qualified to comment on a particular species (i.e., confident of this species' identification in the field, and familiar with the types of habitat in which this species is likely to occur within the zone(s) the person is qualified to comment on).

If at any stage in this assessment you realize that you do not have sufficient information to make a decision that will determine where to proceed next in the assessment. STOP!

Indicate on the front of the response form which answer is unknown and try to recommend who might be able to provide the answer.

Certain species currently existing in Florida or not yet known here are prohibited by federal or state laws. IFAS faculty will not recommend such species and should note their prohibited status when discussing them. Relevant lists of such species can be found at:

\section{USDA / APHIS - Federal noxious weed list}

http://www.aphis.usda.gov/plant_health/ plant_pest_info/weeds/downloads/weedlist2006.pdf

\section{Dept. Agric. and Consumer Services - Noxious weed list}

https://www.flrules.org/gateway/ readFile. asp sid $=0 \&$ tid $=3023798 \&$ type $=1 \&$ File $=5 B-$ 57.007.htm

\section{Florida Fish and Wildlife Conservation Commission- Prohibited plant list}

http://www.myfwc.com/WILDLIFEHABITATS/ InvasivePlants_AquaticPlantPermitRules.htm\#62C$52.011 \% 20$ Prohibited $\% 20$ Aquatic\%20Plants.

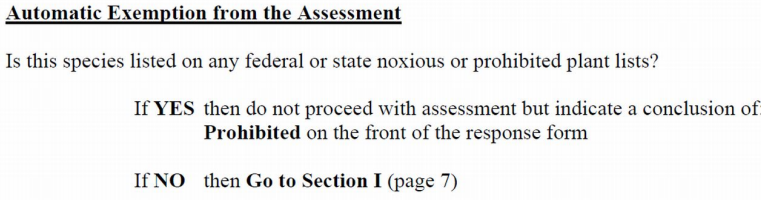

\section{Section I Invasion Status}

The purpose of this section is to separate species that do not appear to invade natural habitats from those that do. For this assessment, a species is defined as invading if it forms self-sustaining and expanding populations within a natural plant community with which it had not previously been associated (cf. "invasive" in Vitousek et al. 1995). This definition does not specify that the species must cause some defined impact (as is required by some definitions) because this will be addressed separately.

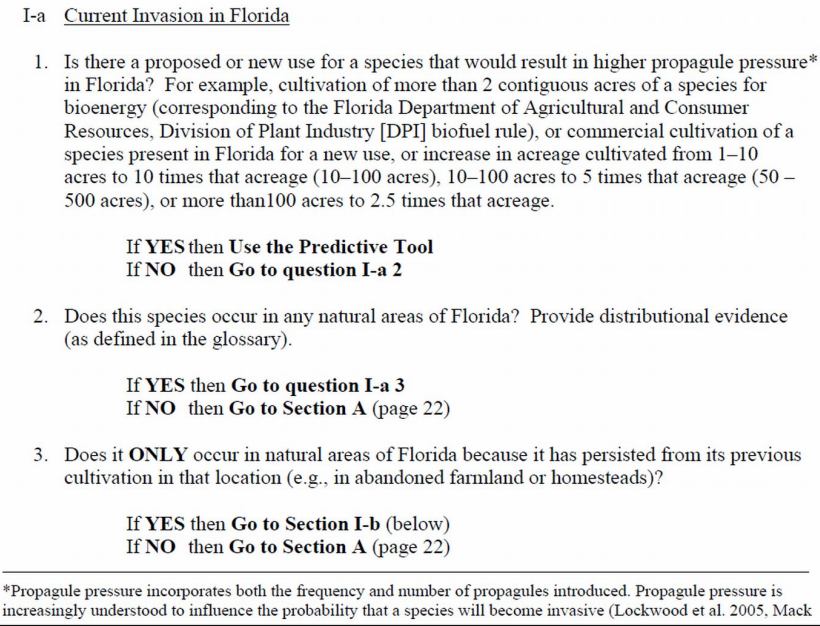

3. Does it ONLY occur in natural areas of Florida because it has persisted from its previous cultivation in that location (e.g., in abandoned farmland or homesteads)?

If YES then Go to Section I-b (below) If NO then Go to Section A (page 22)

*Propagule pressure incorporates both the frequency and number of propagules introduced. Propagule pressure is *Propagule pressure incorporates both the frequency and number of propagules introduced. Propagule pressure is
increasingly understood to influence the probability that a species will become invasive (Lockwood et al. 2005, Mack

\section{I-b Invasion Status in Three Zones of Florida}

Some species may be invading all parts of the state, while others can invade one zone (e.g., sub-tropical south Florida) but may not be able to invade or survive in other zones. A few species may be found currently in only one zone but have the potential to continue to spread to others. Having determined the invasion status of the species on a state-wide basis in Section I-a, determine indices for Ecological Impacts (Section II) and Potential for Expansion (Section III) separately for each of three latitudinal zones so that conclusions can be proposed that account for varying latitudinal and environmental patterns of invasion. In zones where a species is not currently invading, only Potential for Expansion will be evaluated (Section III). 
The state of Florida has been divided into three phytogeographic regions based on an estimated chill accumulation chart. We have modified that map to separate zones at the northern borders of counties that lie along the 420 chill unit accumulation (north) and and the southern borders of counties along the 110 chill unit accumulation (south). These zones are similar to those defined by USDA Hardiness Zones 8, 9 and $10 / 11$

(http://www.usna.usda.gov/Hardzone/index.html).

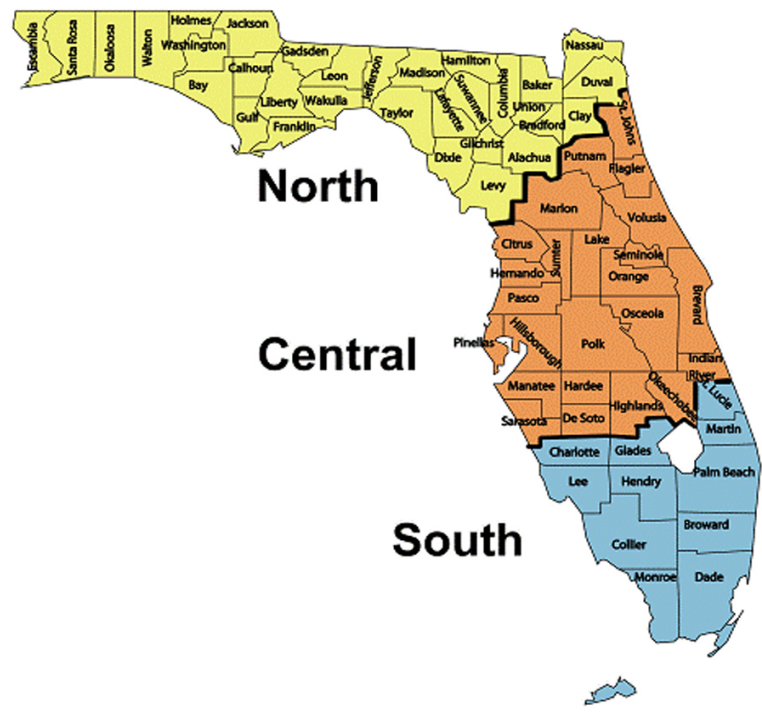

While no areas of Florida are wholly undisturbed by human activity (e.g., air pollution, trails, fragmentation), this assessment is confined to species that invade natural areas in which that anthropogenic disturbance is minimal, or species that may persist in natural communities once anthropogenic disturbances have been largely removed.

Natural systems are dynamic because of a number of natural disturbances on various scales (e.g., gopher mounds, treefalls, fire, tides, flooding, hurricanes, etc.). Altering the frequency and scales of those natural disturbances may allow establishment of new species; it presents as much of a perturbation to the system as does introducing a completely new anthropogenic disturbance (e.g., trampling, grazing animals, soil movement, drainage, pollution, etc.). If a species invades only when disturbance regimes other than those under which the community evolved occur, and if that species is not known to persist when the natural regime is reestablished, the species will not have critical impacts in natural areas being managed to restore or maintain natural processes. For example, skunk vine (Paederia foetida) can invade sandhills that have been fire suppressed, but it is quickly killed and is maintained at low levels when fire is restored to that system. (Note: skunk vine can also invade undisturbed areas and non fire-adapted habitats, so it would still be categorized as invading in Section I-b.)

A species that can establish and persist when natural disturbance regimes exist may pose a serious threat to natural systems. Non-native species that do not require an anthropogenic or other novel disturbance for establishment are pre-adapted to Florida's natural systems and may out-compete native species also adapted to those systems.

\footnotetext{
I-b Invasion Status in Three Zones of Florida

Determine responses to the following questions for one zone (north, central, south) at a time.

Distributional evidence (as defined in the glossary) for invasion (forming self-sustaining and expanding populations within a plant community with which it had not previously been associated) must be provided for YES answers to questions $1-3$.

1. Does this species exist in any areas outside its current or former location of cultivation in this zone?

If YES then Go to question I-b 2 If NO then Go to question I-b 4.

2. Is this species invading in this zone ONLY when natural disturbance regime and scale have been altered? (e.g., where frequency, extent, or severity of fires have been reduced by human activity.)

If YES then Go to question I-b 3.

If NO or Unknown then Go to Section II (page 10)

3. Has this species ever been KNOWN to persist, following colonization, when the natura regime is resumed and the natural flora/communities recover? (e.g., it is not an early successional species that only temporarily invades disturbed areas)

If YES or Unknown then Go to Section II (page 10) If NO (known not to persist) then Go to question I-b 4.

4. Are there other zones in which this species: EITHER has invaded when there was no alteration of the natural disturbance regime, OR has persisted following the restoration of natural disturbance regimes?

If YES then Impact score $=0$ for this zone and Go to Section III-b (page 14) If NO then Go to Section A (page 22)

\section{Section II Ecological Impacts of Invasion}

The purpose of this section is to evaluate the severity of ecological impacts caused by an invasion. This evaluation is made without regard to the actual size or age of an invasion and is independent of any assessment of value or cost of the species. Because we are defining invasion without a requirement for impact (see Section I), it is possible in this assessment for a species to have been identified as 
invading natural habitats but to score low or zero on the Ecological Impact scale (e.g. remains at a low density in an existing stratum of vegetation). Other species may show multiple impacts, which will result in a high score.

In the first part of this section, the worst known impacts of a species are assessed regardless of whether these worst impacts are widespread.

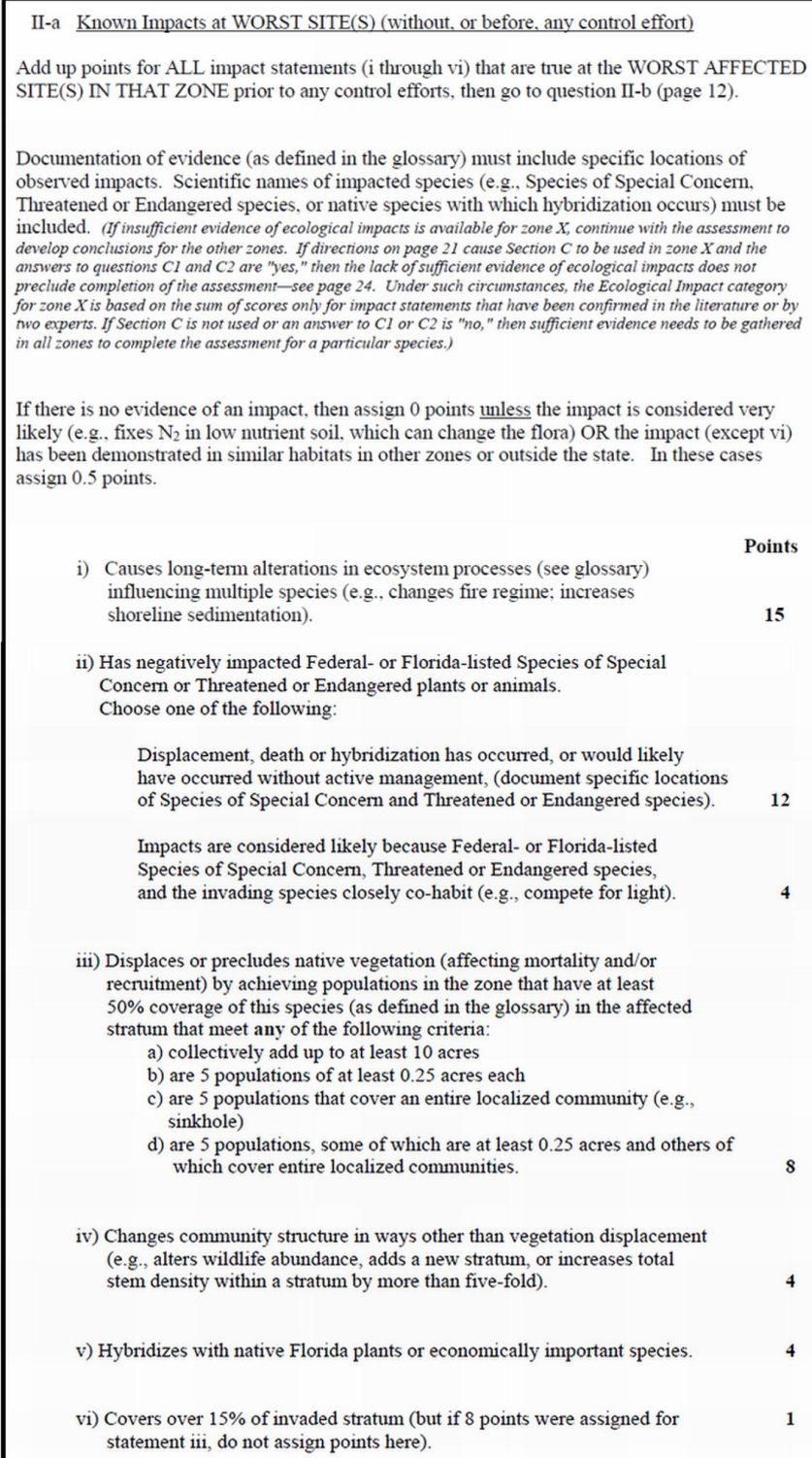

i) Causes long-term alterations in ecosystem processes (see glossary) influencing multiple species (e.g., changes fire regime; increases shoreline sedimentation)

ii) Has negatively impacted Federal- or Florida-listed Species of Special Concern or Threatened or Endangered plants or animals. Choose one of the following

Displacement, death or hybridization has occurred, or would likely have occurred without active management, (document specific locations of Species of Special Concern and Threatened or Endangered species).

Impacts are considered likely because Federal- or Florida-listed Species of Special Concern, Threatened or Endangered species, and the invading species closely co-habit (e.g., compete for light).

iii) Displaces or precludes native vegetation (affecting mortality and/or recruitment) by achieving populations in the zone that have at least $50 \%$ coverage of this species (as defined in the glossary) in the affected stratum that meet any of the following criteria:

a) collectively add up to at least 10 acres

b) are 5 populations of at least 0.25 acres each

c) are 5 populations that cover an entire localized community (e.g., sinkhole)

d) are 5 populations, some of which are at least 0.25 acres and others of which cover entire localized communities.

iv) Changes community structure in ways other than vegetation displacement (e.g., alters wildlife abundance, adds a new stratum, or increases total stem density within a stratum by more than five-fold).

v) Hybridizes with native Florida plants or economically important species.

vi) Covers over $15 \%$ of invaded stratum (but if 8 points were assigned for statement iii, do not assign points here).

\section{II-b Range of Communities in Which Species is Invading}

Species that are capable of invading a wide range of communities are likely to have wide environmental tolerances and broader impacts than those species that are limited to a narrow range of communities. The following lists of community groups have been adapted from the Natural Community Groups defined by the Florida Natural Areas Inventory (FNAI and FDNR 1990). These groups are described at: http://www.fnai.org/PDF/ Natural_Communities_Guide.pdf

\section{$\underline{\text { Terrestrial List }}$}

Xeric uplands- Sandhill, scrub, xeric hammock

Coastal uplands- Beach dune, coastal berm, coastal grassland, coastal rock barren coastal strand, maritime hammock, shell mound

Mesic uplands- Bluff, slope forest, upland glade, upland hardwood forest, upland mixed forest, upland pine forest

Rocklands- Pine rockland, rockland hammock, sinkhole

Mesic flatlands- Dry prairie, mesic flatwoods, prairie hammock, scrubby flatwoods

\section{Palustrine (wetland) / Aquatic List}

Wet flatlands- Hydric hammock, marl prairie, wet flatwoods, wet prairie

Seepage wetlands - Bay gall, seepage slope

Floodplain wetlands - Bottomland forest, floodplain floodplain forest, floodplain marsh, floodplain swamp, freshwater tidal swamp, slough, strand swamp, swale

Basin wetlands- Basin marsh, basin swamp, bog, coastal interdunal swale, depression marsh, dome swamp

Lakes and rivers- All types of freshwater lakes, rivers and streams

Tidal wetlands- Marine and estuarine tidal marshes and swamps 
II-b Range of Community Groups in Which Species Has Impacts

Is this species known to be invading at least four community groups $\mathrm{OR}$ does it occur in at least one community group of each of the terrestrial and palustrine/aquatic lists? (Within each zone, different community groups that are identified by various sources or experts are additive.)

If YES then Multiply total score from II-a by 1.5 .

If score is 12 or greater, Go to Section II-c (below); If score is lower than 12, Go to Section III-a (page 13)

If NO then Multiply total score from II-a by 1

If score is $\geq 12$ Go to Section II-c (below); If score is $<12$, Go to Section III-a (page 13)

\section{II-c Proportion of Invaded Sites with Significant Impacts}

This section is intended to separate those species that do not cause serious impacts everywhere they occur but only in very specific regions or environments. Such species may be acceptable for use in areas that are sufficiently distant from the specific communities they impact (Section B, page 23). It is important to estimate the proportion of sites where worst-case impacts have been recorded, relative to all sites within the zone where the plant has been invading.

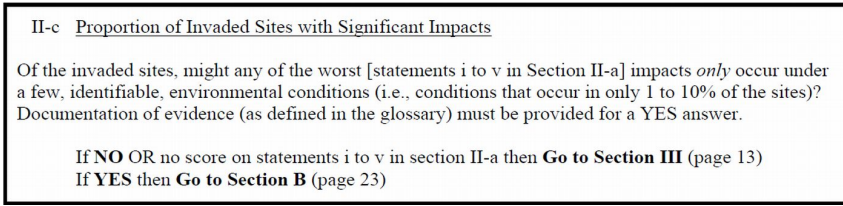

\section{Section III Potential for Expansion.}

The purpose of this section is to provide a crude evaluation of whether there is high or low potential for this species to expand much further within Florida. This assessment is made independently for zones where the plant has invaded, and zones where it has not invaded. The assessment is made without regard to absolute areas of invasion or potential habitats. A high potential for expansion is indicated if there is a significant rate of spread of the species. This section is important for species that may have only recently invaded and for which little evidence of impacts may be available. It is also important for assessing the species' potential for expansion and causing impacts in zones which it is not currently invading.

\section{Question III-a ONLY for Zones Where Plant Has Invaded.}

\section{III-a Known Rate of Invasion.}

Doubling times and absolute areas can be difficult to quantify, so this section uses the concept of "discrete populations" to indicate the rate of habitat invasion. Discrete populations (populations separated by at least 1 mile - see glossary) are intended to be units that are easy to quantify and that probably indicate invading plant populations that arose by long-distance dispersal mechanisms. The rate at which new populations for a species are reported may be as much influenced by increased search effort as by actual expansion of plant coverage. However, this parameter is included because such change in reporting is typical of recently identified species, which are also most likely to have the greatest potential to expand beyond their current distribution.

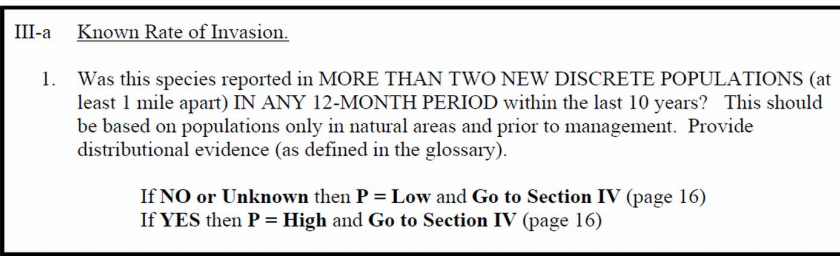

\section{Question III-b ONLY for Zones Where Plant Has NOT Invaded.}

\section{III-b Potential for Invading Non-invaded Zones}

If a species is capable of surviving, reproducing, and dispersing in a zone, then it is likely that its current absence from that zone is a function of its rate of expansion from the place where it was introduced to the state. Its potential for expansion if it reaches a suitable new zone is likely to be high if its potential in currently invaded zones is high.

\section{Question III-c ONLY for Zones Where Plant Has NOT Invaded but Has the Potential To Invade.}

\section{III-c Potential for Causing Ecological Impacts in Non-invaded Zones}

The purpose of this section is to identify the likelihood of future ecological impacts in a zone that 
Documentation of evidence or provision of distributional evidence (as defined in the glossary) must be provided for a YES answer

III-b Potential for Invading Non-invaded Zones

1. Would this species be able to survive, reproduce, and disperse in the CLIMATE of this zone (e g. based on comparisons of climate maps for Florida and worldwide locations where the species is known to occur, including invaded zones and/or native range)?

If NO then $\mathbf{P}=$ Low and Go to Section IV (page 16)

If YES then Go to question III-b 2.

2. Do HABITAT TYPES suitable for the growth of this species occur in this zone (e.g., based on species' known occurrence worldwide within invaded zones or native range)?

If NO then $\mathbf{P}=$ Low and $\mathbf{G o}$ to Section IV (page 16)

If $\mathbf{Y E S}$ then $\mathbf{P}$ for this non-invaded zone is equal to $\mathbf{P}$ assigned to the nearest invaded zone (from Section III-a--if there is an option between two zones with $\mathbf{P}=$ High or Low, use High).

If an adjacent zone is invaded then Go to Section III-c (page 15) If the only adjacent zone is non-invaded then Go to Section IV (page 16)

has not yet been invaded but that has the potential to be. If there is no reason to believe that the ecological impacts observed elsewhere in the state could not occur in this zone, then it is reasonable to adjust the ecological impact score to match that of an adjacent invaded zone, which will lead to similar conclusions for the two zones.

Documentation of evidence or provision of distributional evidence (as defined in the glossary) must be provided for a YES answer.

III-c Potential for Causing Ecological Impacts in Non-invaded Zones

1. For zones invaded by this species, identify all communities in which any ecological impacts identified in Section II-a occur. Do these communities occur in the uninvaded zone under consideration (e.g., do the negatively impacted Federal- or Florida-listed Species of Special Concern. Threatened species or Endangered species occur in this zone)? If no impacts were documented in any zones for this species, the response here zone)?

If NO then Go to Section IV (page 16)

If YES then revise the Ecological Impact Score for this zone from zero to match the Ecological Impact Score for the adjacent invaded zone (use highest value if there is an option; mark this revised score with brackets \{\} to show this score was derived from Section III-c) then Go to Section IV (page 16)

\section{Section IV Difficulty of Management Management Index}

It seems unlikely that management difficulty will vary significantly by zones so this section is assessed on the state-wide distribution of the species, not by zones. The intention of this section is to distinguish species for which management is especially difficult. For most statements, no particular methods of control are specified but responses should relate to the methods that are most likely to be used. Most of these statements relate to the availability of control methods, factors that influence the cost of control (over multiple generations, if relevant), or factors that indicate the increasing likelihood of unavoidable non-target damage. Management of species that become reproductive in a short period of time, or that produce many, long-lived and/or widely dispersed reproductive propagules, is more difficult because they will require more frequent, longer-lasting, and/or more widely ranging re-surveys and re-treatments.

Biological control can greatly reduce management costs, and several effective programs for biological control of non-native plants have been implemented in Florida. Because target plant species for biological control programs have, to date, been on Florida's Prohibited Aquatic Plants List (maintained by Florida Department of Environmental Protection) or Noxious Weeds List (maintained by Florida Department of Agriculture and Consumer Services), and because listed prohibited plants are automatically exempted from the assessment (page 6), neither the use nor the results of biological control are specifically addressed in this section.

Note: This section is assessed on the state-wide distribution of the species, NOT by zones.

\section{Section V Economic Value Value Index}

The intention of this section is not to identify attributes that must apply to every high-value species but to find parameters that indicate the species is of some significant value. Few data are available at the species level on plant production and sales in Florida so it is difficult to develop simple questions for which appropriate information can be found. Sales from chain retail stores may only relate to a few growers but it is likely that these will be high-income species because the chain stores will only select species that they are confident will be popular and sell quickly (especially department and grocery stores).

Note: this section is assessed on the state-wide distribution of the species, NOT by zones.

\section{Conversion of Index Scores to Index Categories}

The actual scores for each index will be important if species are to be compared with each other or over time. For the purposes of reporting the status of a species for each index and for determining the appropriate conclusion, the index scores are converted to index categories. For Potential for Expansion, Management Difficulty, and Economic 


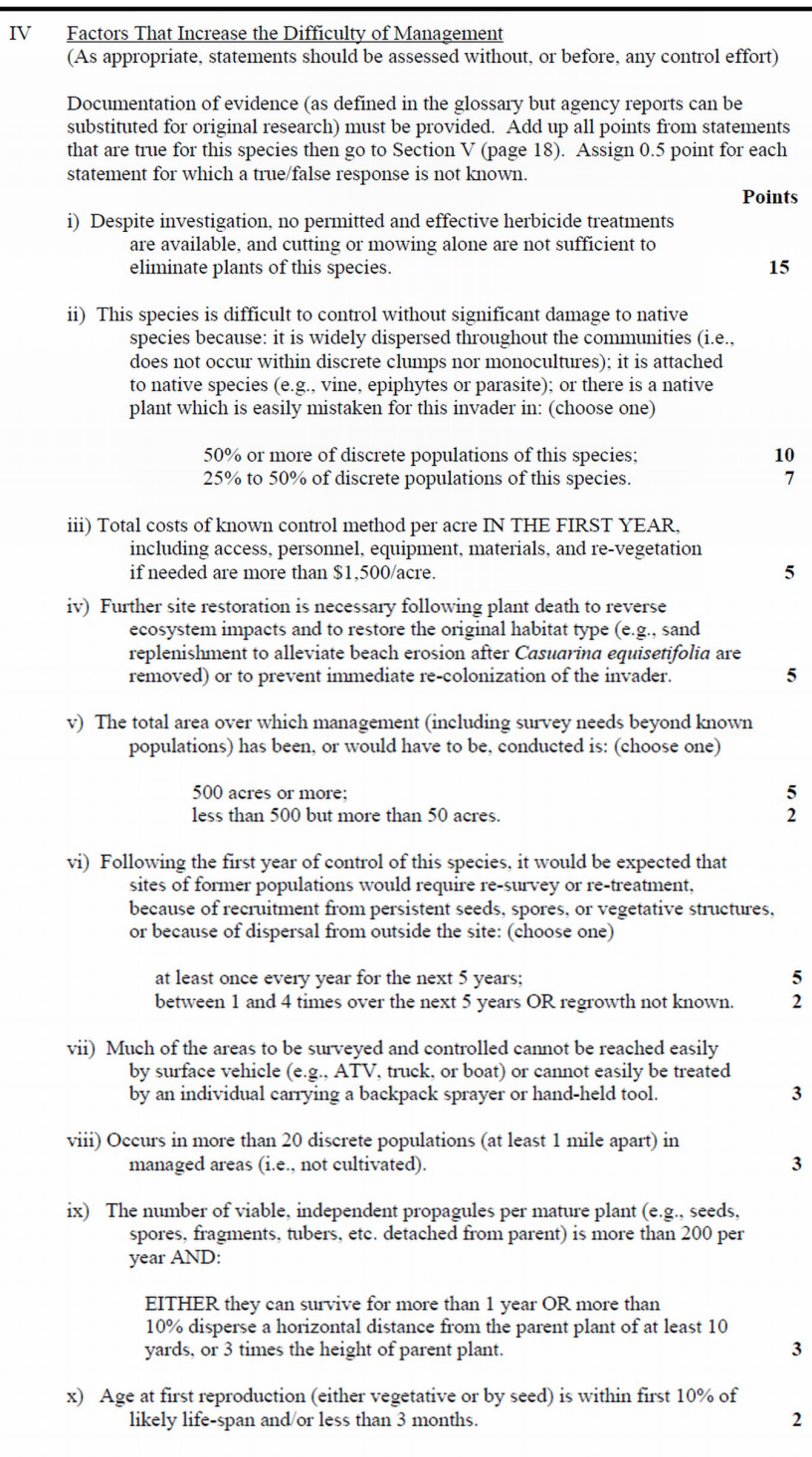

Value there are only two categories (Low or High). For Ecological Impacts there are four categories (Low, Medium, High and Very High).

The criteria for the Impact score cut-offs for each category are based on the combinations of statements that are scored in Section II-a on pages $10-11$. Low impacts include only one mid-scoring statement (8 points) or one to three low-scoring statements ( 1 or 4 points), usually without a wide habitat range.

Medium impacts have at least one high-scoring statement (12 or 15 points), a mid- and low-scoring statement, multiple low-scoring statements, or a wide habitat range. Most High impacts include an ecosystem effect and/or wide habitat range, plus at least one of the other high-scoring statements or several other low-scoring statements. Very High impacts must show ecosystem effects and either all

\section{Economic Value}

Does this species have any economic value in Florida?

If NO then write $\mathbf{V}=$ No on Response Form, but treat as Low in the conclusions table on page 21. Then Go to Conversion of Index Scores to Index Categories (page 19)

If $Y E S$ then Go to question V - 2.

Is this species sold in national or regional retail stores (e.g., WalMart, Home Depot, Publix supermarkets)?

If response is YES then $\mathbf{V}=\mathbf{H i g h}$ and Go to Conversion of Index Scores to Index Categories (page 19)

If response is NO then Go to question $\mathrm{V}-3$.

State-wide are there more than 10 commercial growers of this species (search "Plant Locators." For example sources see Other Resources on page 28)?

If response is YES Then $\mathbf{V}=$ High and Go to Conversion of Index Scores to Index Categories (page 19)

If response is NO then Go to question V- 4 .

Does this species have economic value for forage, biomass, or remediation purposes?

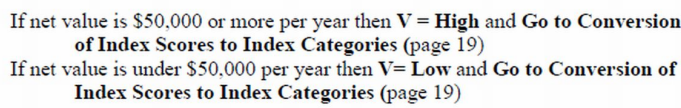

other impacts or a wide habitat range, or must have all impacts other than ecosystem and must have a wide habitat range.

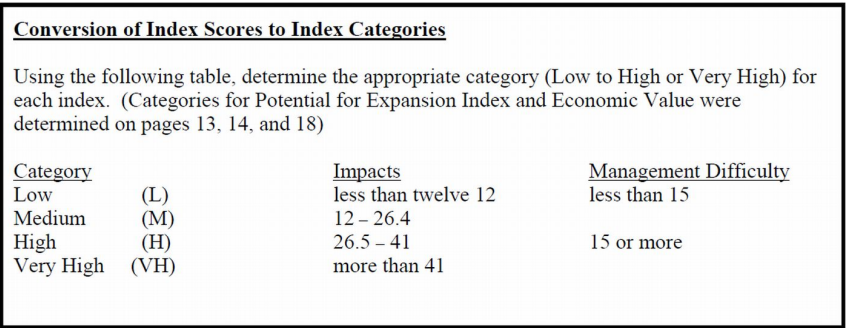

NOTE: The following conclusions would be subject to any local laws, rules, or ordinances that prohibit the sale, transportation, or use of particular species. This may apply to species that are highly problematic in some zone(s), but that have caused minimal impact and have low potential for spread into another zone.

\section{Conclusions For Zones where conclusions were NOT already developed in Section D}

Conclusions are derived separately for each zone from the combined index categories using the table on page 21. Whenever new information becomes available about the invasive status of a species (e.g., new populations, new data on ecological impacts) that species should be reviewed and if necessary reassessed. The following text corresponds to the abbreviations in the table on page 21 (text in bold is 
approved language for IFAS documents, text in parentheses provides additional instructions to IFAS faculty and for reassessment):

\section{$O K=$}

Not considered a problem species at this time (may be recommended by IFAS faculty and reassess in 10 years).

\section{Caution $=$}

Caution - manage to prevent escape (may be recommended by IFAS faculty and reassess in 2 years).

\section{No - unless specified use approved $=$}

In the zones to which this conclusion applies, a species may be eligible for a proposal for specified and limited use, as detailed in Section D.

If a proposal for specified and limited use has not been approved by the IFAS Invasive Plants Working Group (IPWG) the conclusion is:

\section{Invasive and not recommended by IFAS}

faculty (reassess in 10 years-a proposal for specified and limited use may be submitted to the IPWG at any time). In IFAS publications, reference can be made to the website

http://plants.ifas.ufl.edu/assessment to determine if any specified and limited uses have been approved since the time of publication.

If a proposal for specified and limited use has been approved by the IPWG the conclusion is:

Invasive and not recommended by IFAS faculty except for the "specified and limited" use that has been approved by the IFAS Invasive Plants Working Group (reassess in 10 years or 2 years if specified use)

\section{OR}

Predicted to be invasive*: Recommended only under specific management practices agreed upon by the IFAS Invasive Plant Working Group (reassess in 2 years).
In IFAS publications the term "specified and limited" would be replaced by a summary of the specific use that has been approved (e.g., indoor foliage). Details of approved specified and limited uses are to be kept with other assessment documentation.

$$
\text { No }=
$$

Invasive and not recommended by IFAS faculty (reassess in 10 years).

* Reported invasiveness in environments similar to but outside of Florida is one basis for this conclusion

\begin{tabular}{|c|c|c|c|c|c|c|c|}
\hline \multicolumn{3}{|c|}{ 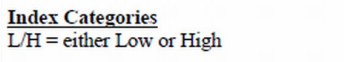 } & \multicolumn{5}{|c|}{ See page 20 for full text for conclusions } \\
\hline Impact & Potential & Manage. & Value & No & $\begin{array}{c}\text { No } \\
\text { unless } \\
\text { limited use } \\
\text { approved }\end{array}$ & Caution & $O K$ \\
\hline $\mathrm{VH}$ & $\mathrm{L} / \mathrm{H}$ & $\mathrm{L} / \mathrm{H}$ & $\mathrm{L} / \mathrm{H}$ & $*$ & & & \\
\hline $\begin{array}{l}\mathrm{H} \\
\mathrm{H} \\
\mathrm{H} \\
\mathrm{H} \\
\mathrm{H} \\
\mathrm{H} \\
\mathrm{H} \\
\mathrm{H}\end{array}$ & $\begin{array}{l}\mathrm{H} \\
\mathrm{H} \\
\mathrm{H} \\
\mathrm{H} \\
\mathrm{L} \\
\mathrm{L} \\
\mathrm{L} \\
\mathrm{L}\end{array}$ & $\begin{array}{l}\mathrm{H} \\
\mathrm{H} \\
\mathrm{L} \\
\mathrm{L} \\
\mathrm{H} \\
\mathrm{H} \\
\mathrm{L} \\
\mathrm{L}\end{array}$ & $\begin{array}{l}\mathrm{L} \\
\mathrm{H} \\
\mathrm{L} \\
\mathrm{H} \\
\mathrm{L} \\
\mathrm{H} \\
\mathrm{L} \\
\mathrm{H}\end{array}$ & $\begin{array}{l}* \\
* \\
* \\
* \\
*\end{array}$ & $\begin{array}{l}*^{1} \\
* 1 \\
*^{1}\end{array}$ & & \\
\hline $\begin{array}{l}\mathrm{M} \\
\mathrm{M} \\
\mathrm{M} \\
\mathrm{M} \\
\mathrm{M} \\
\mathrm{M} \\
\mathrm{M} \\
\mathrm{M}\end{array}$ & $\begin{array}{l}\mathrm{H} \\
\mathrm{H} \\
\mathrm{H} \\
\mathrm{H} \\
\mathrm{L} \\
\mathrm{L} \\
\mathrm{L} \\
\mathrm{L} \\
\mathrm{L}\end{array}$ & $\begin{array}{l}\mathrm{H} \\
\mathrm{H} \\
\mathrm{L} \\
\mathrm{L} \\
\mathrm{H} \\
\mathrm{H} \\
\mathrm{L} \\
\mathrm{L}\end{array}$ & $\begin{array}{l}\mathrm{L} \\
\mathrm{H} \\
\mathrm{L} \\
\mathrm{H} \\
\mathrm{L} \\
\mathrm{H} \\
\mathrm{L} \\
\mathrm{H}\end{array}$ & $\begin{array}{l}* \\
* \\
*\end{array}$ & $\begin{array}{l}* 1 \\
* 1 \\
* 1 \\
* 1 \\
* 1\end{array}$ & & \\
\hline $\begin{array}{l}\text { L } \\
\text { L } \\
\text { L } \\
\text { L } \\
\text { L }\end{array}$ & $\begin{array}{l}\mathrm{H} \\
\mathrm{H} \\
\mathrm{H} \\
\mathrm{H} \\
\mathrm{L} \\
\mathrm{L}\end{array}$ & $\begin{array}{l}\mathrm{H} \\
\mathrm{H} \\
\mathrm{L} \\
\mathrm{L} \\
\mathrm{L} / \mathrm{H}\end{array}$ & $\begin{array}{l}\mathrm{L} \\
\mathrm{H} \\
\mathrm{L} \\
\mathrm{H} \\
\mathrm{L} / \mathrm{H}\end{array}$ & & & $\begin{array}{l}*^{2} \\
*^{2} \\
* 2 \\
*^{2}\end{array}$ & $*^{2,3}$ \\
\hline \multicolumn{8}{|c|}{$\begin{array}{l}\text { Footnotes: } \\
\text { II the zones to which this conclusion applies, a species may be eligible for a proposal for } \\
\text { specified and limited use, as detailed in Section } \mathbf{D} \text { (page } 25 \text { ). }\end{array}$} \\
\hline \multicolumn{8}{|c|}{$\begin{array}{l}2 \text { If a zone is invaded and has Impact }=\text { Low but the adjacent zone has Impact }=\text { High or Very High } \\
\text { or has received an Invasive and not recommended by IFAS faculty OR Invasive and not } \\
\text { recommended by IFAS faculty except for the "specified and limited" use that has been } \\
\text { approved by the IFAS Invasive Plants Working Group conclusion via Section C, then for the } \\
\text { invaded zone under consideration Go To Section C (page 24). }\end{array}$} \\
\hline \multicolumn{8}{|c|}{$\begin{array}{l}3 \text { For zones where a species has not invaded, if Potential = Low but Impacts in an adjacent invaded } \\
\text { zone are Medium, High, or Very High, then use Caution--manage to prevent escape for the un- } \\
\text { invaded zone. If Impact = Low in the adjacent zone or it is not yet invaded, then retain the } \\
\text { conclusion Not considered a problem species at this time. }\end{array}$} \\
\hline
\end{tabular}

\section{Section A (from Section l-a page 7 or Section I-b page 9)}

The purpose of this section is to identify species that pose a threat of genetic invasion of Federal- or Florida-listed plants or economically important species, and to identify for further assessment species that have either been introduced recently or that may have the potential to cause problems based on experiences in similar regions of the world. Plants that do not fall into any of these categories are not 
considered invasive at this time but should be reassessed every 10 years or if invasion into natural areas is recorded.

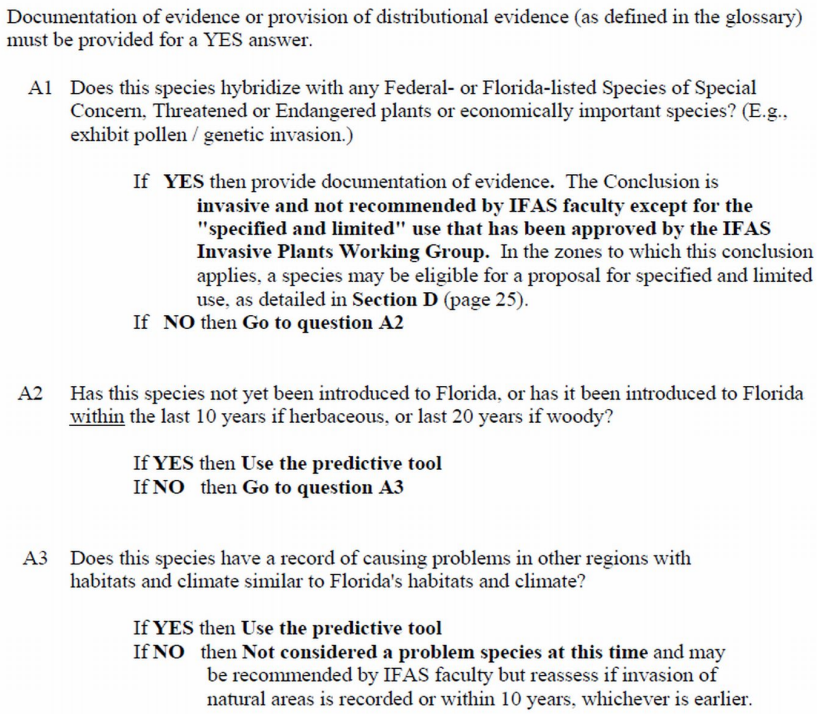

A2 Has this species not yet been introduced to Florida, or has it been introduced to Florida within the last 10 years if herbaceous, or last 20 years if woody?

If YES then Use the predictive tool

If NO then Go to question A3

A3 Does this species have a record of causing problems in other regions with habitats and climate similar to Florida's habitats and climate?

If YES then Use the predictive tool

If NO then Not considered a problem species at this time and may be recommended by IFAS faculty but reassess if invasion of natural areas is recorded or within 10 years, whichever is earlies.

\section{Section B (from Section II-c page} 12)

The purpose of this section is to determine whether the locations in which impacts of the invading species are high can be clearly defined. If impacts are restricted to an identifiable habitat or community, the species may not be recommended for use near those areas. Dispersal characteristics are evaluated to determine how far away a no-plant zone would have to extend to reasonably ensure that propagules would not reach a site that is susceptible to damaging invasion.

\section{Section C (from Footnote 2 on page} 21)

For a zone that is invaded and has Impact $=$ Low but where the adjacent zone has Impact $=$ High or Very High, this section addresses the concern that some of these species have just arrived in a zone and so have not yet become severe enough to be causing ecological impacts in that zone. If the same species had NOT yet been detected in this zone, but were considered likely to survive and cause impacts there, the conclusion would match that for the nearest invaded zone (via Section III-c). For example, in 2001, Paederia foetida in the south zone fit this

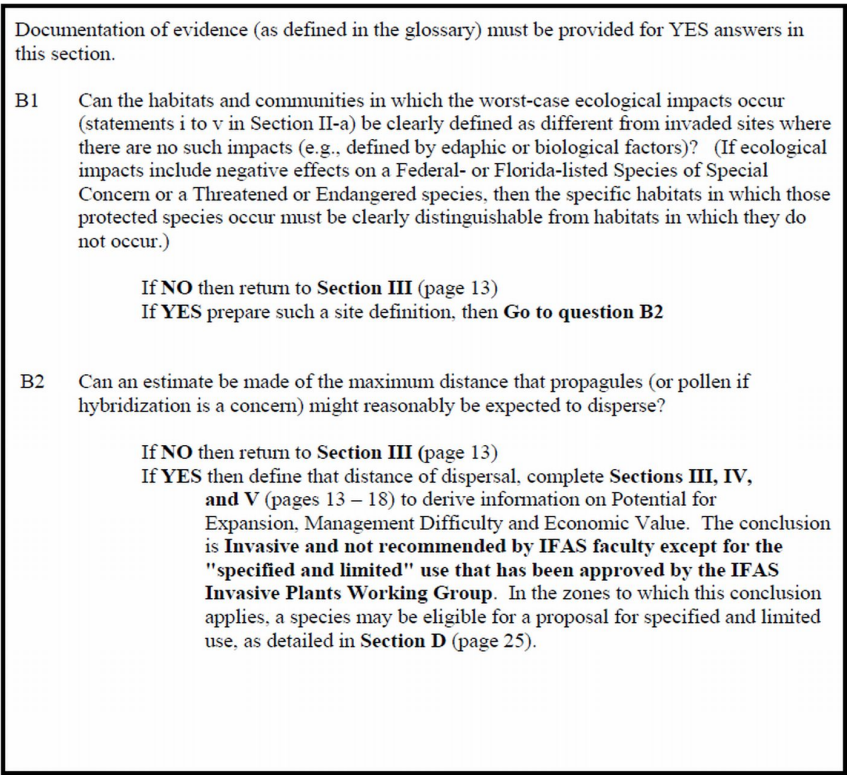

category as a single, new population was first recorded in 2000 .

All else being equal, then, in zones next to highly impacted areas, invasive species that are near the zone but not yet in it give that zone a higher impact rating than invasive species that have actually arrived in the zone, albeit very recently. This not only seems inconsistent but risks underestimating the threat posed by a species at the earliest stage of invasion, when the most effective control action might be taken. On the other hand, if a species has been known in a zone for a long time but it still causes minimal ecological impacts (e.g., Lantana camara in the north zone) a Caution-manage to prevent escape OR Not considered a problem species at this time conclusion would be appropriate.

\section{Section D (from Section A1, Section $B$, or Footnote 1 on page 21)}

This section provides the possibility of a specified exemption to certain Invasive and not recommended by IFAS faculty conclusions (listed above), based on a reasonable certainty that plants grown in the specified conditions will not be able to escape into natural habitats or into the well-defined habitats in which limited impacts occur. Anyone using this assessment tool should recognize that the proposed conclusions have been developed under the assumption that growers, retailers, and consumers will follow any use specifications made. 
Documentation of evidence or provision of distributional evidence (as defined in the glossary) must be provided for a YES answer.

C1 Was the first record of this species in natural areas of this zone less than 10 years ago if herbaceous or less than 20 years ago if woody?

If YES then Go to question C2

If NO then the conclusion for this zone remains as Caution--manage to prevent escape $O R$ Not considered a problem species at this time.

C2 Can this species reproduce and disperse in this zone?

If YES then the conclusion for this zone is Invasive and not recommended by IFAS faculty OR Invasive and not recommended by IFAS faculty except for the "specified and limited" use that has been approved by the IFAS Invasive Plants Working Group to match the adjacent, highly impacted zone. However, do not alter the Ecological Impact category for this zone from Low or Medium. (Thus, if there is an adjacent non-invaded zone, the Ecological Impact category for that zone will remain Low or Medium.) The assessment for this zone can be considered complete now, even if the "documentation of evidence" requirement for Ecological Impacts is not fulfilled (i.e., there are only one or two expert opinions on this species in this zone).

one or two expert opinions on this species in this zone).
If NO then the conclusion for this zone remains as Caution--manage to prevent escape $O R$ Not considered a problem species at this time

If there are specific circumstances in which this species could be used that would not be expected to result in escape and invasion (e.g., foliage plants that are only used indoors and which can be reasonably prevented, by conspicuous labeling, from use or disposal in the landscape) OR it is possible to define how to avoid dispersal of this species to habitats where its impacts are high (i.e., from Section B), then based on a proposal that is approved by the IFAS impacts are high (i.e., from Section B), then based on a proposal that is approved by
Invasive Plants Working Group (IPWG) the conclusion becomes Invasive and not Invasive Plants Working Group (IPWG) the conclusion becomes Invasive and not
recommended by IFAS faculty except for the "specified and limited" use that has been recommended by IFAS faculty except for the "specified and limited" use that has been approved by the IFAS Invasive Plants Working Group. The proposal for specified and disposal of any propagules must ensure their destruction. Reassess this species in 2 years (or in the case of referrals from Section B, immediately if the incidence of worst-case impacts increases above $10 \%)$.

In IFAS publications the term " specified and limited" would be replaced by a summary of the specific use that has been approved (e.g., indoor foliage)

If no proposal for specified and limited used has been approved by the IPWG, the conclusion is Invasive and not recommended by IFAS and the species should be reassessed in 10 years. A proposal for specified and limited use may be submitted to the IPWG at any time.

\section{Glossary for this Assessment}

Anthropogenic disturbance. Recurring anthropogenic source of soil exposure (e.g., roads, trails, plow lines) and/or vegetation structure change (e.g., mowing) that is not the result of a natural process or that does not mimic a natural process and that causes partial or total destruction of vegetative biomass. Also includes human-induced changes in natural disturbance regime (e.g., changing the severity of fires; fire suppression in fire-adapted communities or fire in communities not adapted to fire; or grazing cattle above the density of native herbivores). In this context, disturbance is likely to facilitate the invasion of rapidly colonizing and persistent species.

Coverage. Visual or quantitative estimate of the relative amount of area in a stratum in which the canopy of the non-native species intercepts light that would otherwise be available for other species in or below that stratum. Estimated cover may be dispersed or continuous in a site. Cover is usually measured when foliage is fully expanded. In the case of species that form a dense, continuous mat of rhizomes or stolons, the percent of the soil surface or upper level occupied by that root mat can be estimated as soil, rather than canopy, cover.

Disturbance. Natural mechanisms that limit biomass by causing its partial or total destruction (e.g., fires caused by lightning; herbivory; flooding; hurricanes).

Discrete populations. A population is a group of individuals of the same species living in the same place that are much more likely to reproduce with one another than with individuals from another population. For the purposes of this assessment, discrete populations must be at least 1 mile apart. They likely arose by separate, long-distance dispersal events.

Distributional evidence. Search floras, databases, herbaria, etc. (for examples see "Floras, etc." in Other Resources on page 28). For each relevant record, document: the source (e.g., database, herbarium); the date; the site; the collector; and any other relevant information. If formal documentation is not available, obtain such information (confirmed in writing) from at least two people who have the expertise to identify the particular species.

Documentation of evidence. One publication including relevant, original research will suffice if data are specific to the taxon and zone(s) under evaluation. If such documentation is not available or needs to be updated, at least three individuals who have expertise on the particular species and zone in question must be identified. If more than three experts have been identified, use the responses that are most precautionary (i.e., worst assessment of impacts or greatest management needs reported), as consistent with the intent of the assessment. Relevant information (confirmed in writing) must be provided by at least two of the three experts to justify a "yes" response to a question, or to support a score-accruing statement. For example, in Sections II-a and IV, scores are summed for all statements that have each been confirmed either in the literature or by at least two experts. In statement II-a i), if two experts indicate that there have been ecosystem changes, 15 
points are assigned for this item even if the experts are reporting different types of ecosystem changes. If data in the literature show that a species causes a particular ecological impact but not in the zone under consideration, expert opinion is still needed. However, an expert could give the opinion that this impact is also likely to occur in the zone, and that could be one of the three expert opinions needed. Records should be kept of all the experts who were contacted for each species and zone, regardless of whether they provided input.

Federal- or Florida -listed. Species that are listed by Federal laws or Florida statutes or rules as Threatened, Endangered or Species of Special Concern within the state of Florida. The list of endangered and threatened species of plants is available at: http://www.doacs.state.fl.us/pi/enpp/botany/images/ Notes2003.pdf

Also species and habitats of special concern that are regulated by Florida Statute include: mangroves (FL statute 403.9321), sea oats and sea grape (FL statute 370.041), cypress trees (FL statute 590.02). Other types of imperiled species are listed at: http://www.myfwc.com/WILDLIFEHABITATS/ imperiledSpp_index.htm

Invading. A species that forms self-sustaining and expanding populations within a natural plant community with which it had not previously been associated (cf. "invasive" in Vitousek et al. 1995).

Invasive. Invading species that cause documented ecological impacts higher than Low (pages 19-21).

\section{Long-term alterations in ecosystem processes.} Examples of ecosystem processes that could be altered: erosion and sedimentation rates; land elevation; water channels; water-holding capacity; water-table depth; surface flow patterns; rates of nutrient mineralization or immobilization; soil or water chemistry; and type, frequency, intensity, or duration of disturbance. For further explanation see Gordon (1998).

Native. Species within its natural range or natural zone of dispersal (i.e., within the range it could have, or would have, occupied without direct or indirect introduction and/or care by humans. Excludes species descended from domesticated ancestors) (Vitousek et al. 1995).

Natural areas. Areas of Florida (public or private) with designated management objectives that include the conservation of native biodiversity. While a range of activities may be conducted on these areas (e.g., prescribed fire, low intensity grazing), those activities are designed to be compatible with the conservation objective. State and local governments and some private landowners, for example, manage natural areas both for economic value (recreation, grazing, forestry or other harvest values) and for conservation values. These areas with multiple uses would be designated as natural areas in the Status Assessment, with clearly identifiable "non-natural" edges disregarded. Species that invade only the identified edges - areas next to to roads, trails, fire lanes, recent dredge spoil, formerly cultivated areas, expanses of bare soil, etc.- - will not be identified as invaders with impacts in natural areas because their persistence and spread is only in these clearly anthropogenically disturbed zones in the natural area. The Status Assessment does require the evaluation of populations of species that not only spread along these disturbed zones but disperse over 10 yards into more intact natural areas: these would be included as invading. Ecological impacts would be assessed only where the population has spread into the intact natural areas and not within the source population in the disturbed or formerly cultivated area.

Pollen or genetic invasion. When a native species is displaced by a non-native species through hybridization.

Sites. Locations that can be distinctly described by name (e.g., named State Park or lake) and may be subdivided into distinct habitats and/or communities (e.g., mesic uplands in Acme Park and rocklands in Acme Park). A site may contain more than one discrete population of a species provided that the populations are at least 1 mile apart.

Stratum. A distinct layer in the architecture of vegetation (e.g., tree canopy, understory shrubs). 


\section{References}

Gordon, D.R. 1998. Effects of invasive, non-indigenous plant species on ecosystem processes: lessons from Florida. Ecological Applications 8: 975-989.

Gordon, D.R., D.A. Onderdonk, A.M. Fox, R.K. Stocker, and C. Gantz. 2008. Predicting Invasive Plants in Florida Using the Australian Weed Risk Assessment. Invasive Plant Science and Management 1: $178-195$

Lockwood, J.L., P. Cassey, and T. Blackburn (2005) The role of propagule pressure in explaining species invasions. Trends Ecol Evol 20: 223-228.

Mack, R.N. (2008) Evaluating the credits and debits of a proposed biofuel species: giant reed (Arundo donax). Weed Sci 56: In press

Pheloung, P.C, P.A. Williams, and S.R. Halloy. 1999. A weed risk assessment model for use as a biosecurity tool evaluating plant introductions. Journal of Environmental 57: 239-251.

Reaser, J.K., L.A. Meyerson, and B. von Holle (2008) Saving camels from straws: how propagule pressure-based prevention policies can reduce the risk of biological invasion. Biol Invasions 10: 1085-1098.

Vitousek, P., L. Loope, C. D'Antonio and S.J. Hassol. 1995. Biological invasions as global change. pp. 213-336 In: S.J. Hassol and J. Katzenberger (eds) Elements of change 1994. Aspen Global Change Institute, Aspen, CO.

\section{Other Resources}

Floras, databases, herbaria, etc.

APIRS Online - Bibliographic database of aquatic, wetland \& invasive plants http://plants.ifas.ufl.edu/
Atlas of Florida Vascular Plants -

Institute for Systematic Botany, University of South Florida. http://www.plantatlas.usf.edu/ - use scientific name search.

\section{Virtual herbarium - Fairchild Tropical Gardens} http://www.virtualherbarium.org/ (Information and instructions for using search engine). To search FTG herbarium directly -

http://www.virtualherbarium.org/vh/db/main.htm

Floristic Inventory of South Florida - Institute for Regional Conservation

http://www.regionalconservation.org

Information may also be obtained by visiting the University of Florida (FLAS) Herbarium Details regarding herbarium visits may be obtained at: http://www.flmnh.ufl.edu/herbarium/flasvasc.htm

Some FLAS herbarium records are available on-line and can be linked through the homepage.

\section{Plant locators}

\section{Florida Nursery, Growers and Landscape Association http://www.fngla.org/}

Search for wholesale commercial availability of a species at:

http://dev.fngla.org/search/searching/index.asp

Tampa Bay Wholesale Growers Association Search for wholesale commercial availability of a species (86 nurseries) at: http://www.tbwg.org/PAL.htm

\section{PLANTFINDER - Betrock's Hortworld website}

Search for wholesale commercial availability of a species in Florida at: http://www.plantfinder.com/availability/ plantavailability1.asp

\author{
Search FL Department of Environmental \\ Protection / FLEPPC Exotic plant database - \\ http://www.eddmaps.org/florida/
}

